\title{
Relation of Parents Economical, Educational and Awareness on Immunization Status of Children Visiting Tertiary Care Centre
}

\author{
LUBNA RIAZ1 ${ }^{1}$, WAQAS ALI KHAN ${ }^{2}$, SHAMAYAL MANDOKHEL ${ }^{3}$, ASFAND TARIQ ${ }^{4}$, NEELAM FARYAD ${ }^{5}$, SHAZIA IRUM $^{6}$ \\ ${ }^{1}$ Assistant Professor \& Head of Department, ${ }^{2}$ Postgrduate Trainee, ${ }^{4}$ Assistant Professor, ${ }^{5}$ Medical Officer, Department of Paediatrics, Shaikh \\ Zayed Hospital Lahore \\ ${ }^{3}$ Assistant Professor \& Head of Paediatric Medicine Unit-2, Balochistan Institute of Child Health Services Quetta \\ ${ }^{6}$ Consultant, Maroof Hospital Islamabad \\ Correspondence: Dr. Lubna Riaz, E-mail: Iubnariaz15@gmail.com Cell 0332-4396954
}

\begin{abstract}
Aim: To determine the immunization status of children 0 to 2 years and factors leading to low vaccination status in children visiting tertiary care center.

Study design: Cross-sectional study

Place and duration of study: Department of Paediatrics Shaikh Zayed Hospital Lahore from $1^{\text {st }}$ November 2019 to $31^{\text {st }}$ April 2020.

Methodology: Five hundred children age between 0-2 years were enrolled after fulfilling inclusion and exclusion criteria.

Results: The mean age was $9.9 \pm 6.1$ months, with mean weight of $7.4 \pm 3.4 \mathrm{~kg}$ and $200(40 \%)$ were male and 300 $(60 \%)$ were female patients. Sixty (12\%) were not vaccinated, $145(29 \%)$ partially vaccinated and 295 (59\%) fully vaccinated. In the distribution by income level $255(51 \%), 180(36 \%)$ and $65(13 \%)$ parents were having low, middle and high income respectively; By education level,155 (31\%) with no education, 140 (28\%) some education and 205 $(41 \%)$ with high education, regarding knowledge of immunization, 50 (10\%) had no knowledge, 215 (43\%)had wrong perception of immunization and 235 (47\%) were fully aware.295 (59\%) had up-to-date immunization

Conclusion: More than half of the study populations were upto date about immunization status. It is also concluded that majority of parents of low-income level and uneducated were unknown about immunization status and majority of middle and high-income level and educated people were partial known or up-to-date about immunization status Keywords: Economical level, Educational level, Awareness level, Immunization status
\end{abstract}

\section{INTRODUCTION}

Immunization is a process in which inoculation of an antigen into the body results in activation of immune system, which protects the body from disease. This process is called vaccination. World Health Organization (WHO) launched Expanded Program of immunization (EPI) in 1974 to improve coverage of vaccine preventable diseases worldwide. According to the WHO report published in 2018, 13.5 million infants were not vaccinated. Third dose of the vaccine was never given to19.4 million infants. ${ }^{1}$ In Pakistan 1-2 years of children who are vaccinated varies from $59 \%$ to $73 \%$. $^{2}$ According to $\mathrm{WHO}$, major factors for incomplete vaccination include lack of parental practical knowledge, Religious/cultural/social beliefs/norms, rumors, lost/unavailable heath card, lack of interest/level of motivation, previous experience at health services and Income/socioeconomic status ${ }^{3}$.

A study in Sindh, revealed that prevalence of complete vaccination in Pakistan is $51.3 \%$ only. ${ }^{4}$ Another study at Muzaffarabad, by Rehman et $\mathrm{al}^{5}$ showed that vaccination completion rate in population was $74 \%$. Furthermore, $59.7 \% 88.8 \%$ and $74.0 \%$ of children between 12-23 months of age in Punjab were given three or more pentavalent doses, three or more OPV doses and at least one measles vaccine dose respectively ${ }^{2}$.

Multiple studies conducted to investigate factors responsible for incomplete vaccination of children. A study conducted in India showed that mother's literacy was not

Received on 03-01-2021

Accepted on 23-04-2021 significantly related with vaccination completion $(p=0.889)$. This also revealed that family's socio-economic status was not associated with vaccination completion $(p=0.212) .{ }^{6}$ A study conducted in Pakistan by Murtaza and his colleagues $^{7}$ using Pakistan Integrated Household Survey/Household Integrated Economic Survey (PIHS/HES) 2001-2002 data collected by the Pakistan Bureau of Statistics (PBS), showed that major determinants for incomplete vaccination were large family size, low literacy rate of head of family or spouse of head of family, distance from the nearest health care facility and low socioeconomic status $(p<0.05)$.

Increased coverage of vaccination is one part of Millennium Development Goals (MDG) set by WHO. ${ }^{8}$ Rationale of this study is that vaccination status of Pakistani population is still low. The previous studies were mostly conducted in rural areas of Pakistan. The population included in our study is from those areas of Lahore which comprise of well-educated people and those having better perception/knowledge regarding vaccination. The study aims to identify obstacles which are contributing to incomplete vaccination in these areas, Furthermore, once reasons for incomplete vaccination have been found, policy makers can focus on children who are at increased risk of incomplete vaccination to improve in MDG indicators which can save children from preventable diseases.

\section{MATERIALS AND METHODS}

This cross-sectional study was conducted at Department of Paediatrics Shaikh Zayed Hospital Lahore from $1^{\text {st }}$ November 2019 to $31^{\text {st }}$ April 2020. Children (male, female) 
between ages of 0-24 months presenting to the vaccination Centre, ward/emergency department/outdoor of Sheikh Zayed Hospital Lahore were included. Incomplete record or unclear histories from parents, no clear vaccination record, allergic to vaccines as per history and medical record, born and brought up abroad in their early life assessed by history and not accompanied by any of their biological parents were excluded. SPSS version 21 was used for entry and analysis of data. Three groups will be compared by using square test to see significance of any variable according to complete vaccination versus incomplete vaccination to address effect modifier by keeping $p<0.05$ as significant.

\section{RESULTS}

The mean age was $9.9 \pm 6.1$ years and mean weight was $7.4 \pm 3.4 \mathrm{~kg}$ and other demographic information was shown in Table 1 . There is significant difference $(P<0.05)$ between immunization status with parent's income, education and knowledge about child immunization programme (Table 2).

Table 1: Distribution of patients with age, sex, weight, income level, education, knowledge, immunization status and card availability

\begin{tabular}{|c|c|c|}
\hline Variable & No. & $\%$ \\
\hline \multicolumn{3}{|l|}{ Age (months) } \\
\hline $0-6$ & 195 & 39.0 \\
\hline $7-12$ & 160 & 32.0 \\
\hline $13-18$ & 65 & 13.0 \\
\hline $19-24$ & 80 & 16.0 \\
\hline \multicolumn{3}{|l|}{ Gender } \\
\hline Male & 200 & 40.0 \\
\hline Female & 300 & 60.0 \\
\hline \multicolumn{3}{|l|}{ Weight (Kg) } \\
\hline $2.5-5.0$ & 185 & 37.0 \\
\hline $5.1-7.5$ & 70 & 14.0 \\
\hline $7.6-10.0$ & 150 & 30.0 \\
\hline $10.1-12.5$ & 70 & 14.0 \\
\hline $12.5-15.0$ & 25 & 5.0 \\
\hline \multicolumn{3}{|l|}{ Income level } \\
\hline Low & 255 & 51.0 \\
\hline Middle & 180 & 36.0 \\
\hline High & 65 & 13.0 \\
\hline \multicolumn{3}{|l|}{ Education level } \\
\hline No education & 155 & 31.0 \\
\hline Some education & 140 & 28.0 \\
\hline High education & 205 & 41.0 \\
\hline \multicolumn{3}{|l|}{ Knowledge } \\
\hline No knowledge & 50 & 10.0 \\
\hline Wrong perception & 215 & 43.0 \\
\hline Fully aware & 235 & 47.0 \\
\hline \multicolumn{3}{|c|}{ Immunization status } \\
\hline Unknown & 60 & 12.0 \\
\hline Partial & 145 & 29.0 \\
\hline UpToDate & 295 & $59.0 \%$ \\
\hline \multicolumn{3}{|c|}{ Availability of vaccination card } \\
\hline Yes & 155 & 31.0 \\
\hline No & 345 & 69.0 \\
\hline
\end{tabular}

Table 2: Correlation of immunization status with parent's income, education and knowledge about child immunization programme

\begin{tabular}{|c|c|c|c|c|}
\hline \multirow{2}{*}{$\begin{array}{c}\text { Immunization } \\
\text { status }\end{array}$} & \multicolumn{3}{|c|}{ Parents Income Level } & \multirow{2}{*}{$\begin{array}{c}P \\
\text { value }\end{array}$} \\
\hline & Low & Middle & High & \\
\hline Unknown & 35 & 19 & 6 & \multirow{3}{*}{0.008} \\
\hline Partial & 89 & 38 & 18 & \\
\hline UpToDate & 131 & 123 & 41 & \\
\hline \multicolumn{5}{|c|}{ Parents education level } \\
\hline & No & Some & High & \multirow{4}{*}{0.007} \\
\hline Unknown & 29 & 18 & 13 & \\
\hline Partial & 55 & 45 & 45 & \\
\hline UpToDate & 71 & 77 & 147 & \\
\hline \multicolumn{5}{|c|}{ Knowledge about immunization programme } \\
\hline & No & Wrong/Partial & $\begin{array}{l}\text { Fully } \\
\text { aware }\end{array}$ & \multirow{4}{*}{0.001} \\
\hline Unknown & 19 & 25 & 16 & \\
\hline Partial & 17 & 76 & 52 & \\
\hline UpToDate & 14 & 114 & 167 & \\
\hline
\end{tabular}

\section{DISCUSSION}

Annually approximately 1 billion children are immunized. It plays vital role in public health which has largest impact on childhood mortality and morbidity rate. However, these rates are not favorable in Pakistan. According to recent data EPI coverage is $80 \%$ for Bacillus Calmette-Guerin (BCG), 85\% for diphtheria pertussis and tetanus (DPT) and Polio and $61 \%$ for measles. ${ }^{9}$ The immunization profile of Pakistan has not achieved expected results. ${ }^{3}$ The EPI programme is facing lots of challenges and implementation. There are multiple factors creating obstacles in delivering this service. Number of studies done at multiple centers which showed number of factors are connected to these unexpected results like mother literacy rate, household income, supply of vaccine, distance of vaccine centers and number of vaccination. ${ }^{7}$ In that context the ultimate decision maker in the question, regarding child's health care is usually the child's biological parent. This shows that parents have significant impact on the goals of childhood immunization programs.

Recognizing the parent's key role in the childhood immunization, the association between immunization status of children and the three parental factors i.e. their education, income and knowledge regarding vaccination have impact on immunization. ${ }^{10}$ This is the underlying rationale for inclusion of these factors.

In our study the mean age was $9.9 \pm 6.1$ months that is comparable to Ramzan et $\mathrm{al}^{11}$ reported that mean age was $7.8 \pm 3.3$ months. While mean weight was $7.4 \pm 3.4 \mathrm{~kg}$ as compared with Ramzan et al ${ }^{11}$ study was $7.2 \pm 7.3 \mathrm{~kg}$. Regarding income level it was $51 \%, 36 \%, 13 \%$ for low income, middle income and high income respectively. A study conducted by Noah et $\mathrm{al}^{4}$ showed high wealth group having more knowledge of immunization as compared to low wealth group i.e. $59 \%$ of richest and $35.1 \%$ of poor while middle class ranges from $49.7 \%$ to $52.2 \%$.

While considering education level we had 31\%, 28\% and $41 \%$ parents with no, some and high education respectively. While Nour et $\mathrm{al}^{9}$ showed no education for 
$43 \%$, primary education $48.5 \%$, secondary or higher education $56.6 \%$ for full vaccination coverage. In another study by Adil et $\mathrm{al}^{12}$ there were $41.5 \%$ parents who had no education and $58.5 \%$ had some education. Regarding knowledge of immunization programme $10 \%$ had no knowledge, $43 \%$ wrong perception and $41 \%$ were fully aware. Adil et al $^{12}$ showed $30 \%$ parents had no knowledge, $55 \%$ partial and $14 \%$ were fully aware. These results are comparable to our study.

In our society full immunization coverage was reported as $59 \%$ which was quite low as compared to China which is $97.1 \%$ to $99.4 \%$ under 4 years ${ }^{13}$ and in New Zealand it is $92 \%$ at 2 years of age ${ }^{14}$ but comparable to the study of Noah et al which is $59.1 \%$ from $12-24$ months.

In our society $12 \%$ parents have unknown immunization status, 29\% partially known and 59\% were UpToDate, that is comparable to Adil et al ${ }^{12}$ showing $58 \%$ parents were UpToDate about vaccination. Inspite of many EPI centers there is low vaccination coverage which indicates need of policy making which overcome these obstacles like implementation of education in parents, improve knowledge regarding immunization programme, offer them free services, and mass immunization campaigns.

The compromised immunization service are mainly due to decreased motivation and doubts (religious and cultural) about the importance of immunizations about the importance of immunization at the recipient level. The service providers thought that the problem of incomplete vaccination. In rural and remote areas because of improper vehicles, unavailability of local vaccinators particularly for females and misplacement of cards are the causes of the low vaccination. To improve the immunization coverage in Pakistan service providers combined with media campaigns propagate awareness and modify rigid behavior of recipients. Vaccine coverage can be enhanced by community-based health education, providing immunization and follow up of families, resulting in decrease in disease burden. Appropriate health education messages should be given regarding vaccination of children to counter this problem.

\section{CONCLUSION}

More than half of the study population were UpToDate about immunization status. It is also concluded that majority of parents of low-income level and uneducated were unknown about immunization status and majority of middle and high-income level and educated people were partial known or UpToDate about immunization status.

\section{REFERENCES}

1. World Health Organization, Expanded programme on immunization (EPI) factsheet 2019: Indonesia 2019.

2. Imran H, Raja D, Grassly NC, Wadood MZ, Safdar RM, O'Reilly KM. Routine immunization in Pakistan: comparison of multiple data sources and identification of factors associated with vaccination. Int Health 2018;10(2):84-91.

3. https://www.who.int/immunization/sage/lmm Basics Epid unimm Final v2.pdf

4. Noh JW, Kim YM, Akram N, Yoo KB, Park J, Cheon J, et al. Factors affecting complete and timely childhood immunization coverage in Sindh, Pakistan; a secondary analysis of cross-sectional survey data. PLoS One 2018;13(10):e0206766.

5. Rehman SU, Siddiqui AR, Ahmed J, Fatmi Z, Shah SM, Rehman A, et al. Coverage and predictors of routine immunization among 12-23 months old children in disaster affected communities in Pakistan. Int $\mathrm{J}$ Health Sci 2017;11(1):1-6.

6. Datta A, Baidya S, Datta S, Mog C, Das S. A Study to Find Out the Full Immunization Coverage of 12- to 23-month-old Children and Areas of Under-Performance using LQAS Technique in a Rural Area of Tripura. J Clin Diagn Res 2017;11(2):LC01-4.

7. Murtaza F, Mustafa T, Awan R. Determinants of nonimmunization of children under 5 years of age in Pakistan. $J$ Family Community Med. 2016;23(1):32-7.

8. https://www.who.int/news-room/fact-sheets/detail/ millennium-development-goals-(mdgs)

9. Nour TY, Farah AM, Ali OM, Abate KH. Immunization coverage in Ethiopia among 12-23 month old children: systematic review and meta-analysis. BMC Public Health 2020;20:1134.

10. Owais A, Khowaja AR, Ali SA, Zaidi AKM. Pakistan's expanded programme on immunization: an overview in the context of polio eradication and strategies for improving coverage. Vaccine 2013;31(33):3313-9.

11. Ramzan A, Moorani KN, Shahid A.Assesment of nutritional status in children attending basic health unit of shidi Goth. Pak J Med Res 2008;47:224-7

12. Adil MM, Zubair M,Alam AY,Khan SM, Ishtiaque ZB, Qureshi AA.Knowledge of mothers about children's immunization status in the urban areas of Islamabad. Rawal Med J 2009;34:33-5.

13. Accessing vaccination coverage, timelins, and its temporal variation s among children ina rural area in china yangni he, yang lio,bingbing dai,liang zhao, jiqun lin, Available at http://doi.org/1.1080/21645515.2020.11772620

14. Ministry of Health. National and DHB immunization data.2019 https://www.health.govt.nz/our-work/prevention health/wellness/immunisation/ immunisation coverage/national and dhb immunization data 